\title{
Microstructure and Texture Evolution During the Direct Extrusion and Bending-Shear Deformation of AZ31 Magnesium Alloy
}

\author{
Xiao-Ye Liu' ${ }^{1}$ Li-Wei Lu ${ }^{1,2} \cdot$ Kun Sheng ${ }^{1} \cdot$ Tao Zhou $^{3}$ \\ Received: 31 July 2018/Revised: 12 October 2018/Published online: 23 November 2018 \\ (C) The Chinese Society for Metals and Springer-Verlag GmbH Germany, part of Springer Nature 2018
}

\begin{abstract}
AZ31 alloys were extruded by direct extrusion and bending-shear deformation (DEBS). The microstructure characteristic and texture evolution of DEBSed AZ31 sheets were investigated by electron backscattered diffraction (EBSD). It is found that DEBS technique could effectively refine grains and weaken texture. Besides, we also investigate how twinning affects dynamic recrystallization during hot extrusion. $\{10-12\}$ extension twins can offer nucleation sites and enough energy to trigger dynamic recrystallization. Moreover, the character of direct extrusion and bending-shear die can lead to the activation of non-basal slip system and further dramatically weaken the basal texture of the microstructure with many preactivated basal slip systems.
\end{abstract}

Keywords Magnesium alloys · Extrusion · Grain refinement $\cdot$ Texture evolution

\section{Introduction}

Mg alloys are considered to be potential ideal substitution materials for steels due to their lower densities, higher specific strengths and better recycling characteristics, meaning that they are more favored for energy saving, environmental protection and other applications [1]. However, the poor mechanical properties and high processing cost have greatly restricted their widespread applications [2].

Grain refinement and texture control are effective ways to improve the properties of magnesium alloys. The improvement in room temperature ductility of magnesium alloys via grain refinement is mainly due to shortening

Available online at http://link.springer.com/journal/40195

Li-Wei Lu

cqullw@163.com

1 Hunan Provincial Key Laboratory of High Efficiency and Precision Machining of Difficult-to-Cut Material, Hunan University of Science and Technology, Xiangtan 411201, China

2 School of Materials Science and Engineering, Central South University, Changsha 410083, China

3 School of Materials Science and Engineering, Chongqing University of Technology, Chongqing 400054, China dislocation slip path and the reduction in non-uniform deformation, which makes it easier for grain rotation and grain boundary movement. Meanwhile, grain refinement can activate the potential non-basal slip systems more effectively in magnesium alloys. However, a strong basal texture often forms during hot plastic deformation due to the opening of the basal slip system, resulting in anisotropic properties of material [3]. In addition to slip, twinning is another important deformation mode of magnesium alloy. According to the previous reports [2, 4], the $\{10-12\}$ extension twinning plays an important role in the deformation of $\mathrm{Mg}$ alloys. Firstly, it adapts to plastic strain, causing a strain hardening and low flow stress rate. Secondly, Hall-Petch hardening by twinning induced change in grain size. Thirdly, twin texture induced slip system activity change [5]. These phenomena indicate that the change in twinning characteristic would have a significant effect on the hot deformation behavior of as-cast materials and the production process of final sheets.

To date, many researches aimed to refine grains by severe plastic deformation (SPD). SPD technology has been conformed to be effective in grain refinement and ductility improvement of magnesium alloys. Among these SPD techniques, equal-channel angular pressing (ECAP) is the most conventional and effective methods to achieve grain refinement and superplasticity in different $\mathrm{Mg}$ alloys [6]. However, ECAP is not a continuous process and 
normally requires $4-10$ passes to obtain a stable uniform microstructure. Moreover, due to the limitation of mold shape, ECAP has great limitations in the preparation of large size $\mathrm{Mg}$ alloy sheet and strip with ultrafine grains, making it difficult for industrial applications [7]. Therefore, ECAP technique is mainly used in the laboratory and need further improvement to expand its application scope.

A variety of special forming methods for $\mathrm{Mg}$ alloys have been developed. Lu et al. [8] proposed an integrated forward extrusion and torsion deformation (FETD) for AZ31 alloys, the grains are refined to $5.5 \mu \mathrm{m}$, and the basal texture is dramatically decreased to 8.32 using a single processing step. Yang et al. [9] found that high density of \{10-12\} twins is activated during plastic deformation, resulting in inhomogeneous microstructure distribution around extrusion joint (EJ) zone. Li et al. [10] used the technique of continuous variable cross-sectional direct extrusion (CVCDE) with three interim dies to process AZ31 magnesium alloy, and the ductility could be greatly improved via refining microstructure and weakening texture. Huang et al. [14] performed one-way repeated bending deformation and subsequent annealing on AZ31B sheet, and it is found that the basal plane of the magnesium alloy sheet can be deflected, weakening the basal texture significantly and thus improving the room temperature ductility.

A new extrusion process, the direct extrusion and bending-shear deformation (DEBS), introduces a continuous bending-shear structure to the direct extrusion for further refining grains and weakening basal texture. Therefore, the present study aims to reveal the grain refinement mechanisms, especially twinning and dynamic recrystallization (DRX) behavior of an AZ31 Mg alloy during DEBS process. Besides, the effects of twinning and DRX on the texture evolution are further discussed.

\section{Experimental}

\subsection{Material}

A commercial AZ31 Mg alloy bar (3.20 wt\% Al, $1.11 \mathrm{wt} \%$ $\mathrm{Zn}, \quad 0.30 \mathrm{wt} \% \mathrm{Mn}, 0.0143 \mathrm{wt} \% \mathrm{Si}, 0.0015 \mathrm{wt} \% \mathrm{Fe}$, $0.0021 \mathrm{wt} \% \mathrm{Cu}, 0.0009 \mathrm{wt} \% \mathrm{Ni}$ and $\mathrm{Mg}$ balance) was used in this work, which was machined into billets with a size of $\varnothing 25 \mathrm{~mm} \times 40 \mathrm{~mm}$ and then homogenized at $400{ }^{\circ} \mathrm{C}$ for $20 \mathrm{~h}$. The billets and DEBS molds were placed in an electric resistance furnace and heated to the target temperature. Hot extrusion was carried out at $370{ }^{\circ} \mathrm{C}$ at a velocity of $2 \mathrm{~mm} \mathrm{~s}^{-1}$. The extrusion process was promptly to conduct with a lubricant of $70 \% 74 \#$ cylinder oil and $30 \% 400$ mesh graphite.

\subsection{Die Structure}

DEBS process principle: Compared with direct extrusion, the key point of DEBS is four-pass bending-shear added after direct extrusion. Bending-shear deformation can accumulate large strains to completely trigger DRX and adjust grain orientation after four-pass bending-shear deformation, weakening the basal texture. All parts of the die were made of the H13 steel. The parameters of the mold cavity structure are shown in Fig. 1a. The direct extrusion ratio and conical angle were 3 and $60^{\circ}$, respectively. And the sample shape was transformed from a bar with a $\varnothing 25 \mathrm{~mm}$ diameter into a sheet with a width and thickness of 25 and $3 \mathrm{~mm}$, respectively. The bending radii $\mathrm{R} 1, \mathrm{R} 2$ and the bending angles were set to be $6 \mathrm{~mm}, 3 \mathrm{~mm}$, $140^{\circ}$ and $100^{\circ}$, respectively.

\subsection{Microstructure Observation}

Microstructure specimens were observed on a FEI Quanta 200 scanning electron microscope (SEM). Specimens for EBSD test were prepared by electro-polishing using $10 \%$ perchloric acid $+90 \%$ ethanol at $15 \mathrm{~V}$ and $-30{ }^{\circ} \mathrm{C}$, and then, the EBSD test was conducted on a CamScan MX 2600 equipped with an HKL Channel 5 software. The corresponding probe current was $60 \mathrm{nA}$, and the orientation imaging microscopy was measured at a step size of $0.1 \mu \mathrm{m}$. The microstructures were observed at the central part of the ED-TD plane using EBSD. Here, ED and TD refer to the extrusion direction and transverse direction of the cubic samples, respectively. The microstructural observation spots are clearly illustrated in Fig. 1b. The characteristic zones of the DEBS deformation were labeled as $\mathrm{A}, \mathrm{B}, \mathrm{C}, \mathrm{D}$ and $\mathrm{E}$, which represent the upsetting zone, the conical zone, the transition zone, the bending-shear zone and the forming zone, respectively.

\section{Results and Discussion}

Figure 2 shows the microstructure of upsetting zone of AZ31 alloy. The misorientations between the matrix and the primary or secondary twins are given in Table 1. At initial stage of deformation, the high density of $\{10-12\}$ twins was observed in the coarse grains, which can promote plastic deformation. The $\{10-12\}$ twin showed different morphologies and orientations in original grains, as shown in Fig. 2a, b. Some twin lamellas pass through the grain boundaries of the large grain leading to some coarse grain refinement, while some twin are truncated by the grain boundary and provide some nucleation sites for DRX in the truncated. To study the effect of twins on DRX, one 

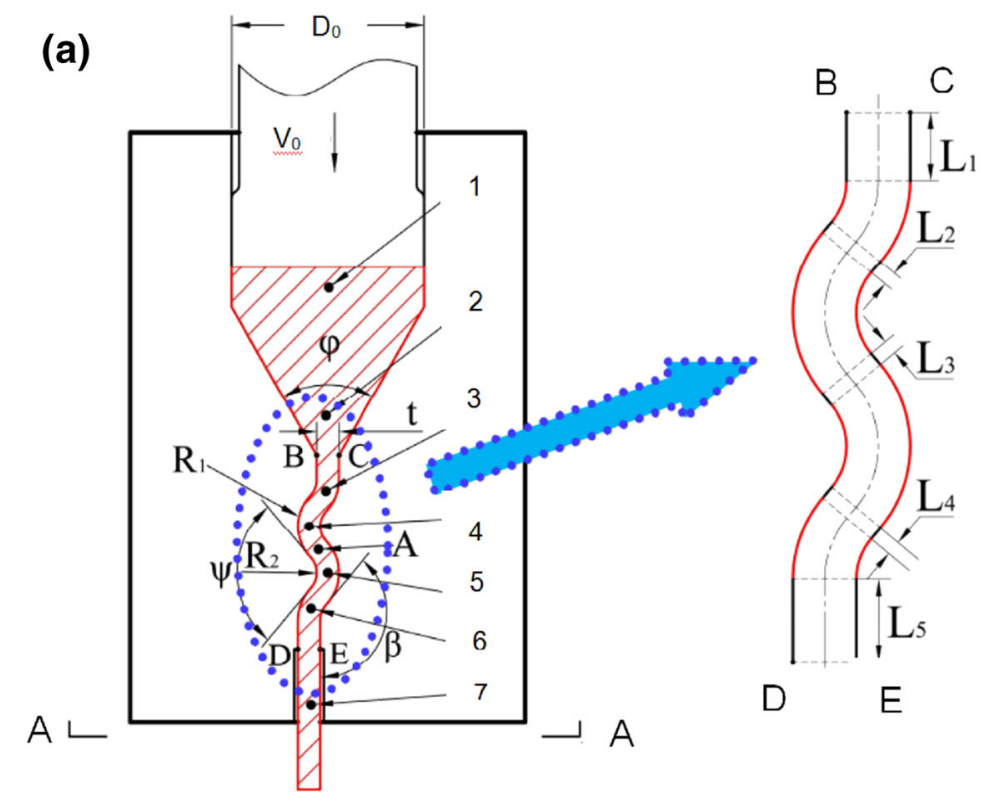

(b)

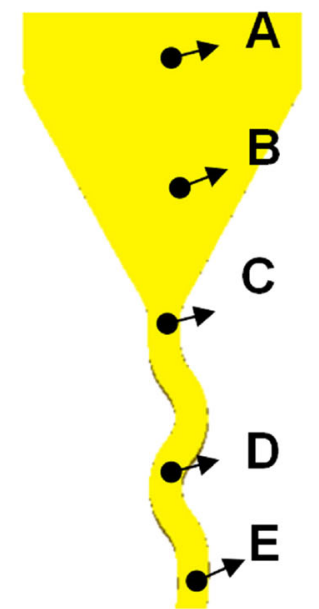

Fig. 1 a Schematic of the DEBS die, b EBSD observation areas

typical area (region 1) in Fig. 2a is selected. The magnified EBSD image (Fig. 2c) clearly shows the intersection of twins and the nucleation of fine DRXed grains around the twins. There exist fine DRXed grains in the twin-like lamellas, and it can be guessed that the DRXed grains of this region are transformed by twinning. We selected several typical grains $\mathrm{a}, \mathrm{b}, \mathrm{c}, \mathrm{d}$ and e to further investigate the relationship between twins and DRXed grains. Figure $2 \mathrm{c}$ shows that the grains $\mathrm{a}, \mathrm{b}$ and $\mathrm{d}$ are DRXed grains, and the grains $\mathrm{c}$ and $\mathrm{e}$ are the parent and twin, respectively. The misorientation angle between grain $\mathrm{d}$ and twin $\mathrm{e}$ is $86.5^{\circ}$, revealing that the parent grain c can be interpreted as $\{10-12\}$ extension twin. The angle between the DRXed grains $\mathrm{d}$ and the twins e is $36.6^{\circ}$, indicating that the DRXed grain a may be induced by twins. Figure $2 \mathrm{c}$ displays the orientations of the individual grains within the band along with their misorientation relationships with the neighboring, deformed matrix, indicating that twins were the preferred sites for DRX compared with grain boundaries [11]. Therefore, twinning plays important roles in the microstructural evolution during the early extrusion stage, which was regarded as twinning-active stage in this work. Figure $2 d$ shows the distribution of the Schmid factor (SF) of the basal slip system. The SF calculated by selecting the crystal grains a, b, c, d and e is shown in Table 2, from which we can see that the SF of the matrix $c$ and twin e is relatively high, while that of DRXed grain $b$ is relatively lower than twins, and the DRXed grains a and $d$ adjacent to twins are higher than twin and matrix. It is indicated that the formation of twins can also coordinate the orientation of the grains, making the grain orientation transferred from "hard" orientation to "soft" orientation to coordinate basal slip deformation. Twinning at this stage predominantly follows the SF criterion with respect to the original orientation of parent grains. As shown in Fig. 2e, many lowangle grain boundaries (LAGBs) are formed at the twin boundary, so the strain at this place is larger than that of other places, as shown in the dotted line.

Figure $3 \mathrm{a}, \mathrm{b}$ shows that not only many twins appear in large grains, but also a lot of fine DRXed grains occur at the coarse grain boundaries. Fine DRXed grains formed at grain boundaries, and their orientations were very close to the surrounding coarse primary grains, which can be determined from the colors in the inverse pole figure maps. Besides, these fine grains were nearly free of LAGBs, further confirming that they are newly formed DRXed grains [12]. There are numerous LAGBs in the AZ31 magnesium alloy for the forward extrusion zone, as shown in Fig. 3a, b. Many sub-grains can be observed inside coarser grains and are elongated in the extrusion direction. The fine grains are gathered together to form band shaped structures. This further confirmed that twins could effectively subdivide the coarse grains, block the dislocation motion and contribute to the accumulation of dislocations, finally forming the sub-grain boundaries (sub-GBs). The materials exhibit a typical bimodal grain structure consisting of fine equiaxial DRXed grains of $<\sim 5 \mu \mathrm{m}$ and coarse unDRXed grains of $>\sim 70 \mu \mathrm{m}$ developed in the sample [13]. Research [4] has shown that deformation strain is more likely to be accommodated by those initial coarse grains that have been transformed into fine ones. As shown in Fig. 3b, after the second extrusion pass, twins are increasingly nucleated in grains and become thicker and longer, indicating that the twins have grown up at this 


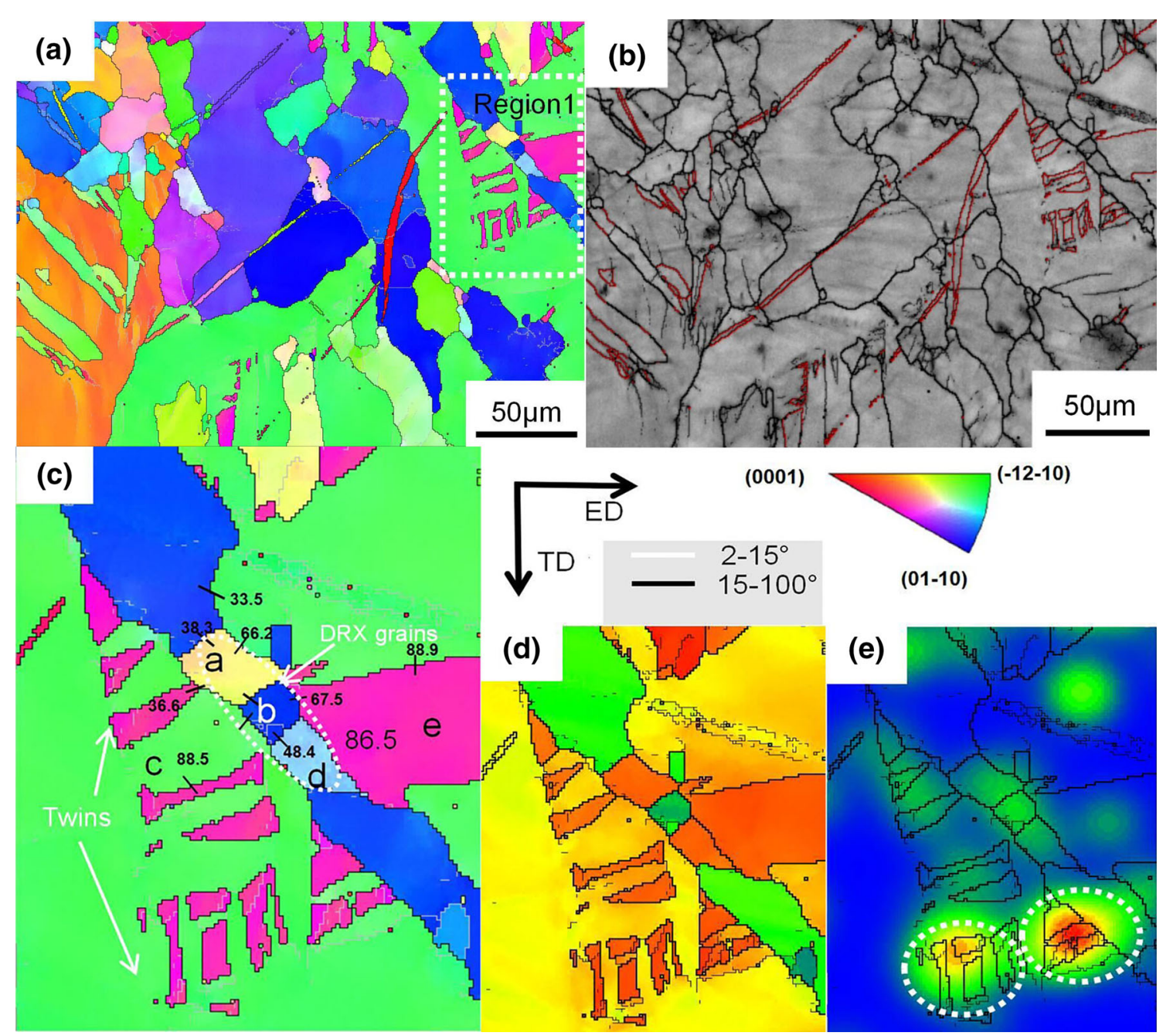

Fig. 2 EBSD maps of upsetting zone: a IPF figure, $\mathbf{b}$ image quality map with twin boundaries, $\mathbf{c}$ IPF map of region 1, d Schmid factor map of basal slip system of region 1 , e strain distribution diagram of region 1

Table 1 Different types of twin and its misorientation angle and axis

\begin{tabular}{ll}
\hline Types of twins & Misorientation angle/axis \\
\hline$\{10-12\}$ extension twin & $86^{\circ}<1-210> \pm 5^{\circ}$ \\
$\{10-11\}$ contraction twin & $56^{\circ}<1-210> \pm 5^{\circ}$ \\
$\{10-11\}-\{10-12\}$ secondary twin & $38^{\circ}<1-210> \pm 5^{\circ}$ \\
\hline
\end{tabular}

Table 2 Schmidt factor of the selected grains

\begin{tabular}{llllll}
\hline Grain number & $\mathrm{a}$ & $\mathrm{b}$ & $\mathrm{c}$ & $\mathrm{d}$ & $\mathrm{e}$ \\
\hline Schmidt factor & 0.13 & 0.41 & 0.44 & 0.2 & 0.4 \\
\hline
\end{tabular}

stage. This further confirms that $\{10-12\}$ extension twins could effectively subdivide the parent grains, block the dislocation motion and contribute to the accumulation of dislocations, finally forming the sub-GBs and DRXed grains [14]. It is interesting to find that there were special microstructures with an twin-like morphology, but the boundaries were LAGBs (less than $15^{\circ}$ ) rather than $\{10-12\}$ twin boundaries, as indicated by dotted lines in Fig. 3e. In Mg alloys, detwinning is a phenomenon that pre-activated $\{10-12\}$ twins tend to narrow or disappear during strain-path changes [15-18]. Ni et al. [19] reported that detwinning deformation can happen through interaction between dislocations and twin boundaries in nanocrystal line grains. The inset of Fig. 3e shows the misorientation angles of detwinning, twins and parents. The misorientation angle between parent $\mathrm{P}$ and twin $\mathrm{T}$ is $86.3^{\circ}$, however, the misorientation angle between parent $\mathrm{P}$ 

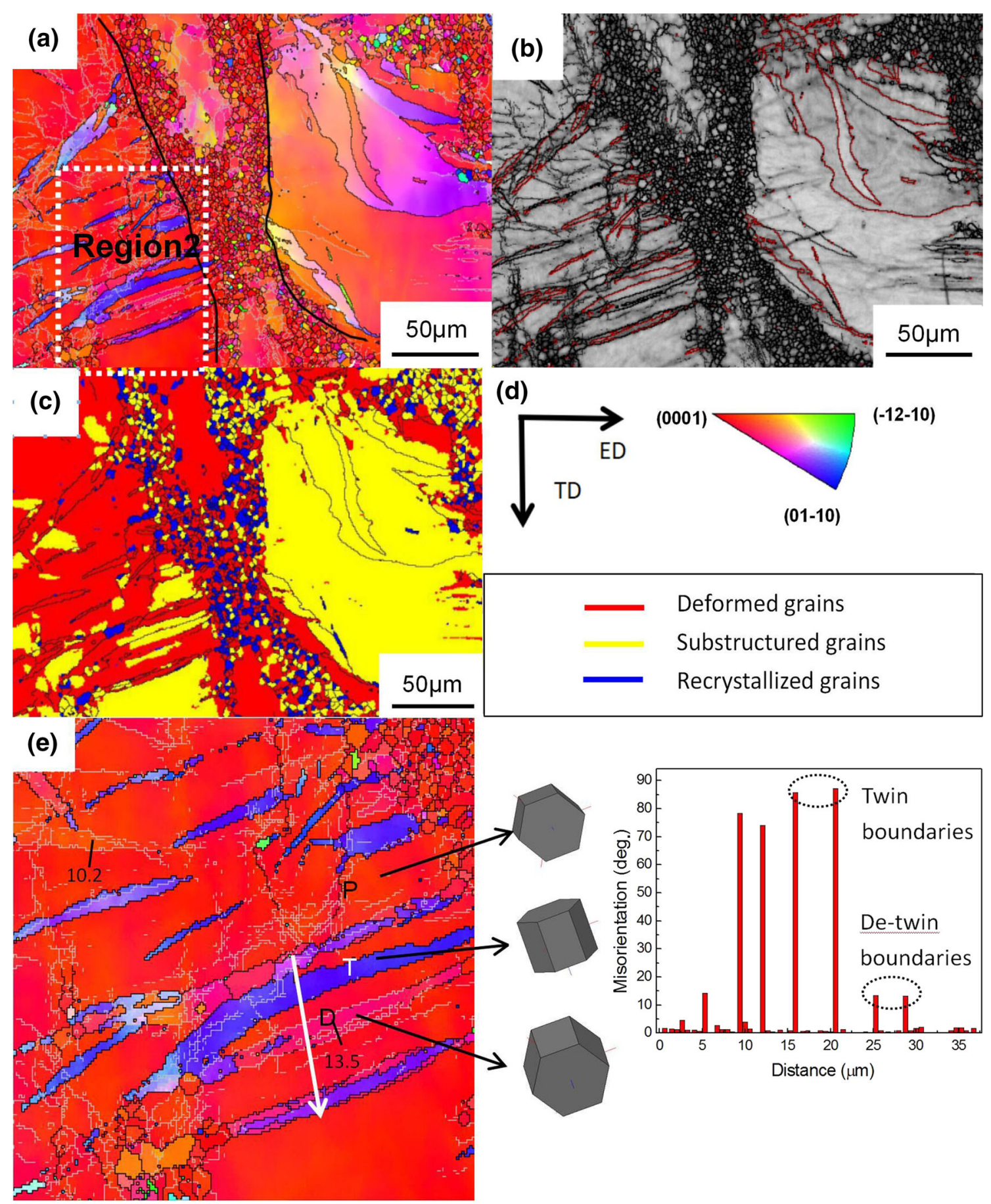

Fig. 3 EBSD maps of conical zone: a IPF figure, b image quality map with twin boundaries; c dynamic recrystallization distribution, d crystallographic map and recrystallization color diagram: deformed grains are in red, sub-structured grains and recrystallized grains, e enlarged map of region 2 and grain orientation three-dimensional diagram

and detwinning $\mathrm{D}$ was $13.5^{\circ}$. It indicates that the transformation of twins into detwinning is accompanied with the transformation of high-angle grain boundaries (HAGBs) into LAGBs, and the detwinning may be dissolved in the parent in the subsequent deformation. It is reported that the occurrence of detwinning restrains the effect of $\{10-12\}$ twin on weakening the basal texture, since detwinning can restore the crystallographic orientation of the twinned region to that of the initial state [20]. This fact further indicates that if the detwinning activity during deformation could be retarded, twinning region will have a relative high volume fraction, improving the effect 
of texture control, which would make this texture control method more attractive and useful. But the reason why twinning and detwinning operate simultaneously in a single twinning system is not clear [21]. In Fig. 3c, the grains rotate under the action of severe strain, but there is no complete DRX. Since twinning could not fully accommodate severe strain, basal slip became the dominant deformation. The grains in blue color disappeared which is due to the rotation of the basal slip system to the $<0001>$ orientation. Besides, $\{10-12\}$ extension twinning is not favored due to the strongly textured grain orientations.

In the transition zone, Fig. 4a shows that the grains have been clearly refined with an average grain size of about $22 \mu \mathrm{m}$. The grain size of AZ31 Mg alloy in the transition zone of DEBS is comparable to that processed by conventional direct extrusion $(20 \mu \mathrm{m})$ [22], while the grain size dramatically decreases to $6.2 \mu \mathrm{m}$ after the subsequent bending-shear deformation. In the case of such a small grain, there are still many twins, as shown in Fig. 4b. Most of these substructural boundaries, however, disappear after being deformed and the prolonged grains evolve, to a large extent, into long strip grains and tiny recrystallized grains at boundaries. In magnesium alloys, twin initiation is related to grain size. According to the Hall-Petch formula
$\left(\sigma=\sigma_{0}+K d^{-1 / 2}\right)$, the larger the grain size, the easier the twin active. In the large grain, the dislocation slip path is far and more likely to cause dislocation pileup at the grain boundaries, resulting in stress concentration. However, the twin yield stress is small, which is easy to induce twin initiation. As the grain size decreases, the twins are inhibited. But as long as the grain size is large enough to accommodate all twin formation, twins can also occur in small grain [23]. According to the previous reports, the presence of twins in small grain with a grain size of $3 \mu \mathrm{m}$ was observed in AZ31 magnesium alloy [24]. Keshavarz et al. [25] believe that for AZ31 magnesium alloys, twinning can occur at the condition of temperature of $373-673 \mathrm{~K}$, strain rates of $0.01-10 \mathrm{~s}^{-1}$ and grain sizes of 2-100 $\mu \mathrm{m}$. The misorientation angle distribution (Fig. 4c) presents the distinguished number fraction peaks for LAGBs, as well as HAGBs between $25^{\circ}-35^{\circ}$ and $83^{\circ}-89^{\circ}$. The high peak in the range of $2^{\circ}-8^{\circ}$ exhibits no dominant rotation axis, which is resulted from LAGBs [26]. The local peak in the range of $25^{\circ}-35^{\circ}$ shows a dominant rotation axis of $<0001>$, which is related to the opening of basal slip system. From the distinguished peaks in the range $83^{\circ}-89^{\circ}$ with the $<12-10>$ axis, it could be further
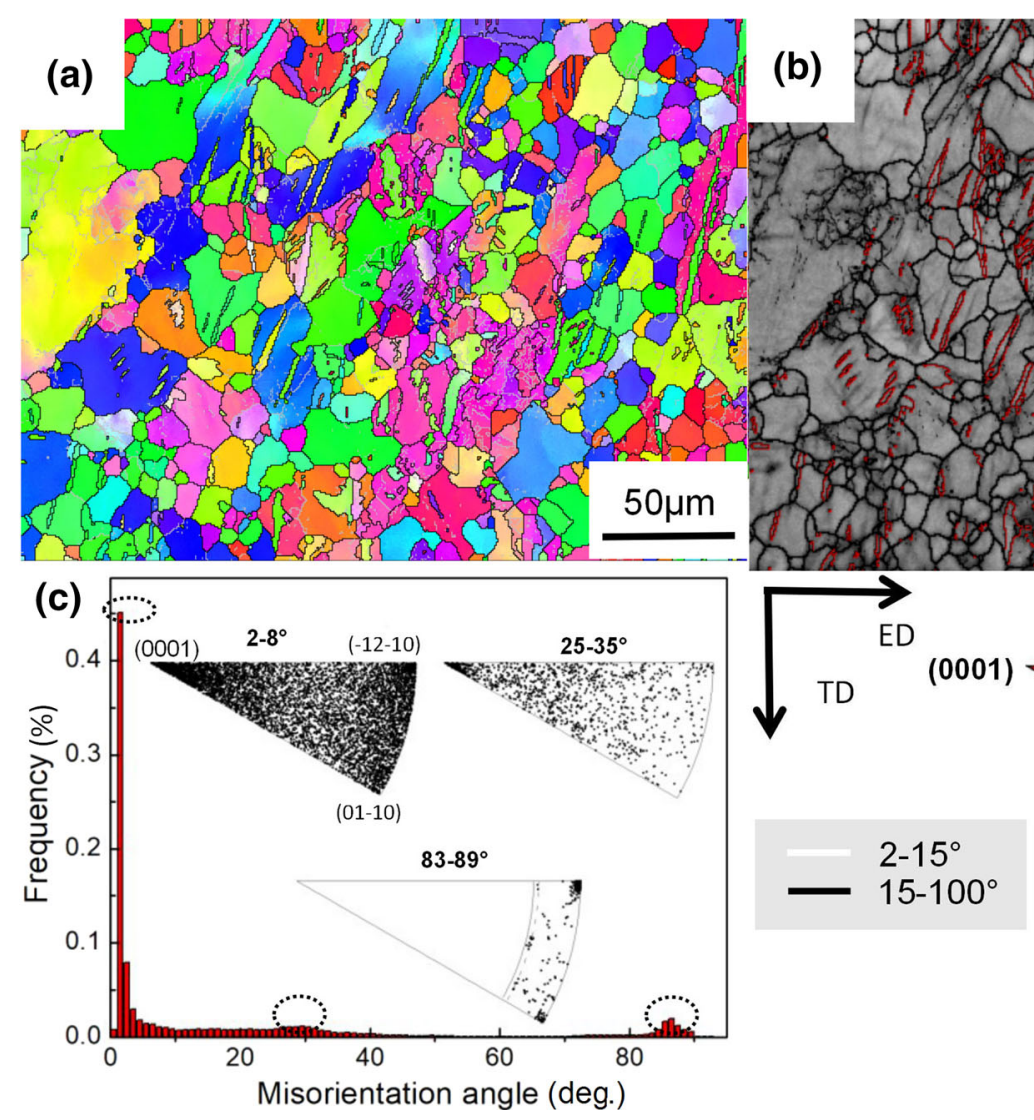

(b)

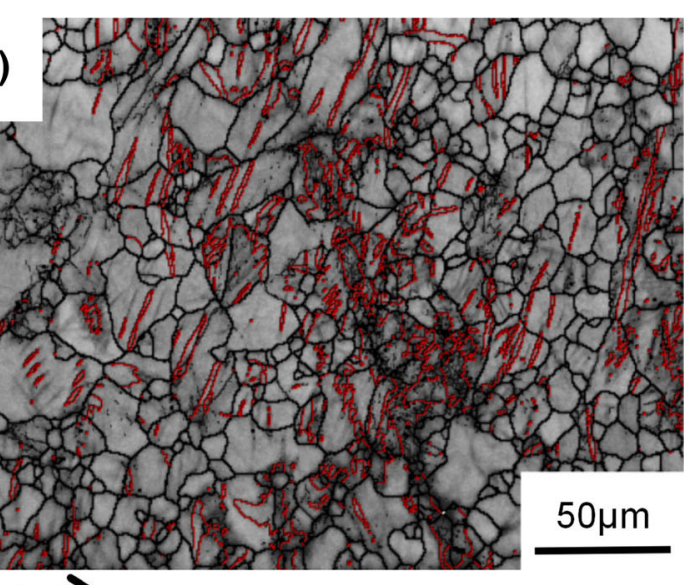

$(-12-10)$

Fig. 4 EBSD maps of transition zone: a IPF figure, $\mathbf{b}$ image quality; map with twin boundaries, $\mathbf{c}$ misorientation distribution of the AZ31 alloy 
confirmed that high density of $\{10-12\}$ twins is activated at this stage [27].

Figure 5a shows that after one bending-shear deformation, the grains are remarkably refined with a grain size of $18 \mu \mathrm{m}$. But there are also some long coarse grains in the sample due to the uneven deformation, as identified by the dotted line in Fig. 5b. Most of these large grains are deformed. The grains were subjected to bending-shear deformation, which causes the grain to undergo further DRX [28]. It can be seen that there exist many LAGBs in these large deformed grains, and these LAGBs can be translated into HAGBs in the next bending-shear deformation to further refine the large grain. At this stage, the twins have completely disappeared. It also can be seen that there is no peak at $86.3^{\circ}$ from the misorientation distribution in Fig. 5c. It was worth noting that the peak of misorientation angle near $30^{\circ}$ was remarkably increased, and the recrystallization and grain growth of HCP materials often resulted in the orientation rotation of $25^{\circ}-35^{\circ}$ around the c-axis [29]. Thus, the higher peak near $25^{\circ}-35^{\circ}$ might be due to the DRX or grain growth during the extrusion [30]. At the same time, the LAGBs are reduced from the previous stage with the DRX process. The basal slip system accounts for the dominant plastic deformation at this stage.
After two bending-shear deformations, both the coarse grains and fine grains have been effectively refined to around $6.2 \mu \mathrm{m}$, as shown in Fig. 6a. It seems that the LAGBs have evolved into HAGBs, and finer grains appear compared with the original as-cast grains. The homogeneity of the microstructure increases with the rise in strain. Bending-shear deformation can bring additional shear stain after the direct extrusion process. Moreover, the results indicate that the inducement of grain size in the AZ31 alloys is mainly by the reason of the DRX; namely, new DRXed grains can be generated by the rotation and combination of twins and sub-grains. By using the bending-shear deformation, the microstructural inhomogeneity is dramatically improved due to the increase in DRX fraction throughout the entire material. Besides, it should be noted that equal-channel angular extrusion (ECAE) can also refine AZ31 grains to $4.2 \mu \mathrm{m}$, but it requires eight passes [26]. However, the DEBS process needs only onepass forming. By comparison, DEBS process is more effective in grain refinement. Some grain bands are in blue, while others grain bands are in red in Fig. 6a, which may be caused by the strain gradient in the conical zone. At the edge of the sample, the strain is big, while there is a small strain in the middle of the sample, resulting in uneven grain
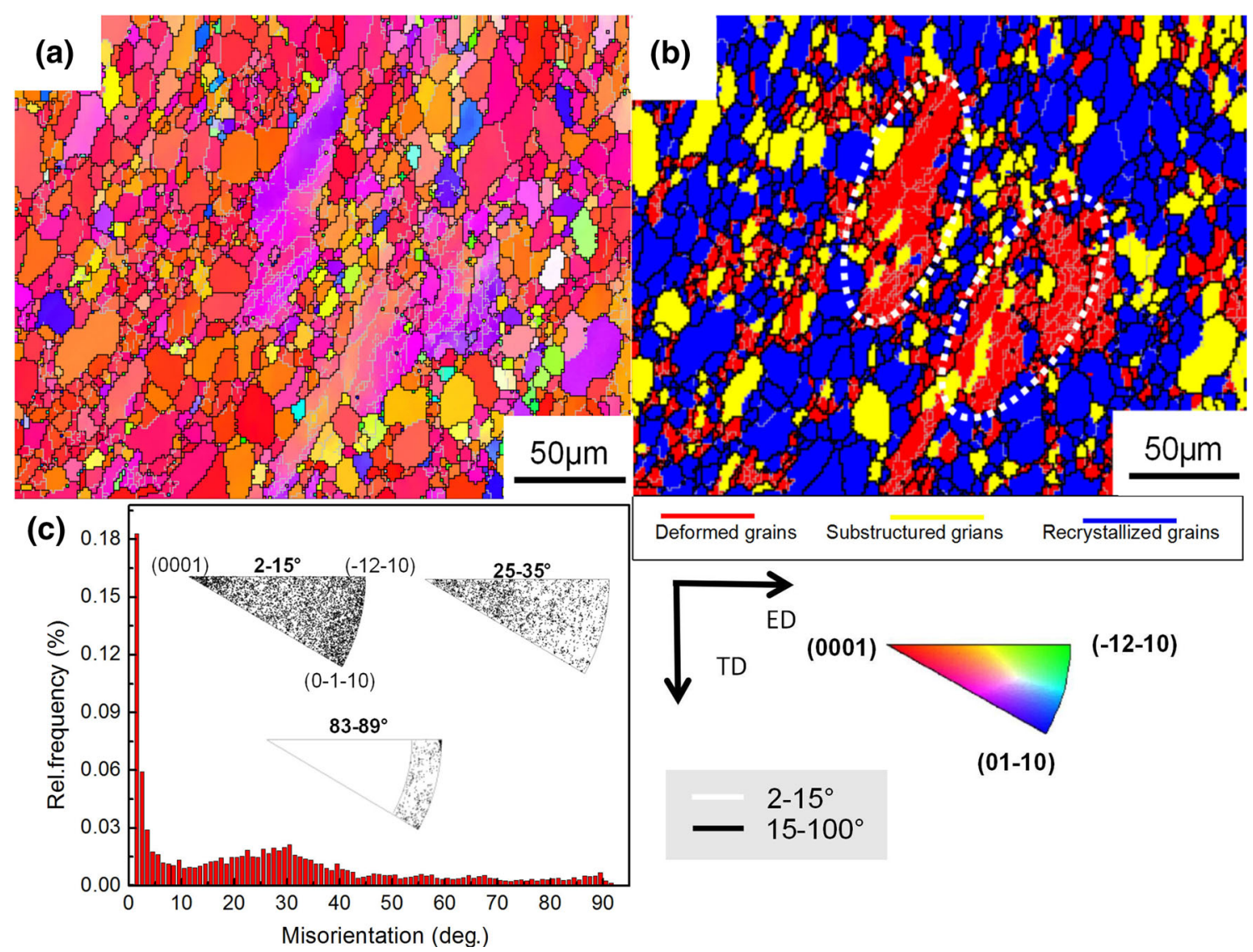

$2-15^{\circ}$

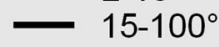

Fig. 5 EBSD maps of bending-shear zone: a IPF figure, $\mathbf{b}$ dynamic recrystallization distribution, $\mathbf{c}$ misorientation distribution 

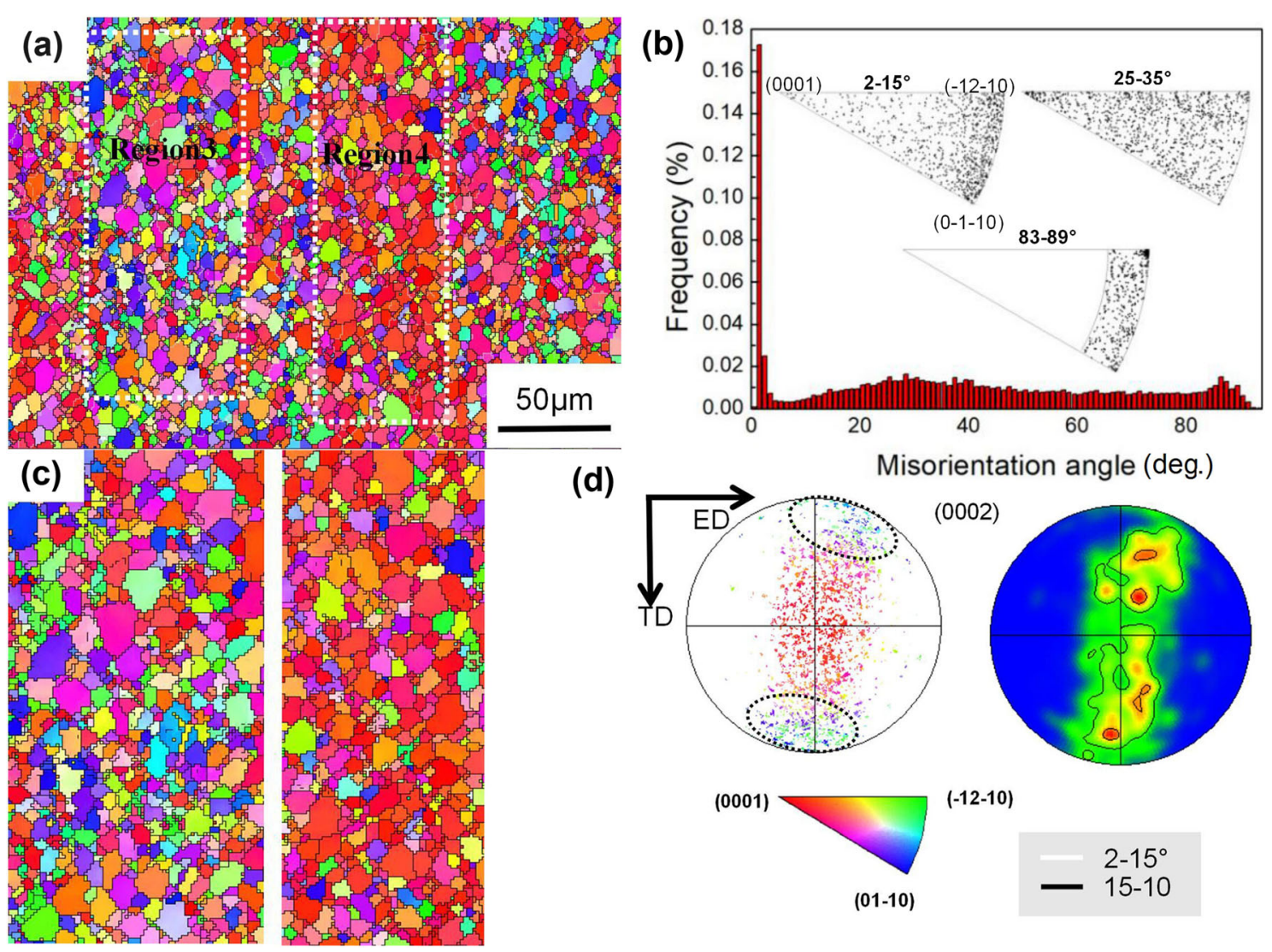

(d)

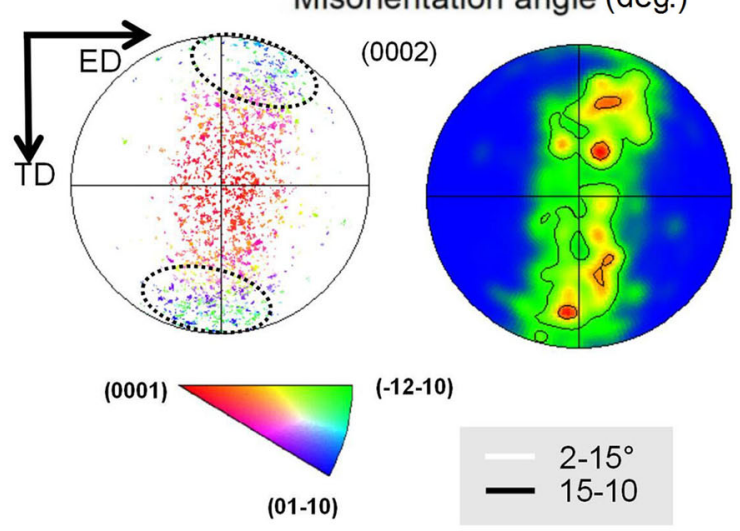

Fig. 6 EBSD maps of forming zone: a IPF figure, $\mathbf{b}$ misorientation distribution of the AZ31 alloys, $\mathbf{c}$ enlarged map of regions 3 and 4, $\mathbf{d}$ pole figure of regions 3 and 4

stress and different grain rotation angles, so eventually blue grains and red grains alternating appeared in the sample. We selected the grains in red and blue in regions 3 and 4, respectively. In the (0002) pole figure, the grains in red are mostly concentrated in the middle of (0002) pole figure, which is parallel to the normal direction (ND) direction. The grains in blue are at the both ends of the circumference, indicating that the red grains contribute to the basal texture formation, while blue grains can weaken the basal texture. This further indicates that DEBS process can produce large deformation under the condition of hot extrusion, prompting the non-basal slip system to open, coordinating the grain orientation and weakening the texture.

The (0002) pole figure of the forming zone obtained from ED-TD plane of the sample is shown in Fig. 7. The AZ31 Mg alloy shows a typical basal fiber texture with intensity of 4.94 and the basal poles show angle distribution of $\pm 35^{\circ}$ away from the TD to the ED. Compared with the upper stage, it is apparent that much randomized textures and the density of the texture are further reduced. Additionally, the middle layer exhibits a weak double-peak texture which is elongated along ED. During extruding
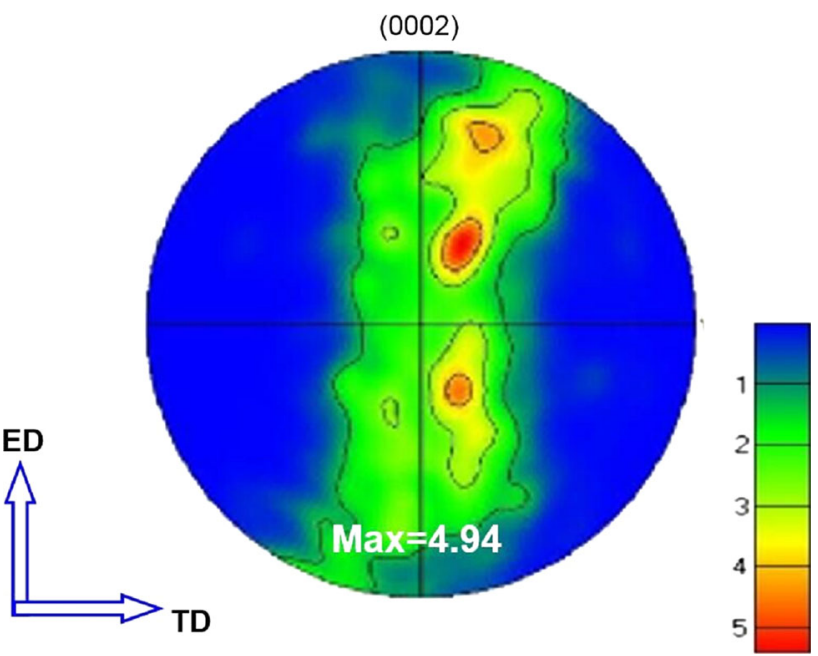

Fig. $7\{0002\}$ pole figure of forming zone

stage, the material flows to the second bending-shear zone and the shearing stress gradually rotates, which leads to the deviation of orientation and the further decrease in texture intensity [31]. On the other hand, the non-basal slip system is activated during the second bending-shear deformation 
and may dominate the plastic deformation in the final stage. The texture intensity decreases from 47.32 to 4.94 , which much less than that of the direct extrusion produced sample (9.686). It manifests that the basal texture can be significantly weakened by successive bending-shear deformation, implying that the DEBS process could effectively weaken the basal texture of AZ31 $\mathrm{Mg}$ alloy sheets. Texture weakening can reduce the anisotropy in the extrusion process, which can obtain a uniform and stable plastic deformation and then improve the ability of plastic forming [32].

\section{Conclusion}

The new SPD technique-DEBS-can effectively refine the grains and improve the microstructure of AZ31 Mg alloy. The grain size is reduced significantly from $253 \mu \mathrm{m}$ to $6.2 \mu \mathrm{m}$ after extrusion only one at $370{ }^{\circ} \mathrm{C}$ due to DRX. Bending-shear deformation is found to be critical to tuning texture of AZ31 alloy due to the opening of non-basal slip system and the initiating of DRX during DEBS, leading to further microstructure homogeneity. The texture evolution manifests that the strong basal texture formed in the direct extrusion can be further weakened by bending-shear deformation. Moreover, the influence of twinning on DRX during hot extrusion further revealed that $\{10-12\}$ extension twins can provide nucleation sites and enough energy for triggering DRX.

Acknowledgements This work was supported partly by the National Natural Science Foundation of China (Grant Nos. 51505143 and 51728202), the Scientific Research Fund of Hunan Provincial Education Department (Grant No. 17B089) and the financial supports from the China Postdoctoral Science Foundation (Grant Nos. 2016T90759 and 2014M562128).

\section{References}

[1] L.W. Zheng, H.H. Nie, W.G. Zhang, W. Liang, Y.D. Wang, Mater. Sci. Eng. A 722, 58 (2018)

[2] M.G. Jiang, H. Yan, R.S. Chen, J. Alloys Compd. 650, 399 (2015)

[3] F. Li, W. Shi, N. Bian, H.B. Wu, Acta. Metall. Sin. (Engl. Lett.) 28, 649 (2015)
[4] F. Li, X. Zeng, G.J. Cao, Mater. Sci. Eng. A 639, 395 (2015)

[5] S.H. Park, S.G. Hong, J.H. Lee, Y.H. Huh, J. Alloys Compd. 646, 573 (2015)

[6] R. Kocich, L. Kuncicka, P. Kral, T.C. Lowe, Mater. Des. 90, 1092 (2016)

[7] Z.D. Zhao, Q. Chen, C.K. Hu, D.Y. Shu, Mater. Des. 30, 4557 (2009)

[8] S.H. Seyed Ebrahimi, K. Dehghani, J. Aghazadeh, M.B. Ghasemian, Sh. Zangeneh, Mater. Sci. Eng. A 718, 311 (2018)

[9] L. Farbaniec, C.L. Williams, L. Kecskes, K.T. Ramesh, R. Becker, Int. J. Impact Eng. 98, 34 (2016)

[10] R. Alizadeh, R. Mahmudi, P.H.R. Pereira, Y. Huang, T.G. Langdon, Mater. Sci. Eng. A 682, 577 (2017)

[11] S.C. Zhao, E.J. Guo, G.J. Cao, L.P. Wang, Y.C. Lun, Y.C. Feng, J. Alloys Compd. 705, 118 (2017)

[12] L.W. Lu, C.M. Liu, J. Zhao, W.B. Zeng, Z.C. Wang, J. Alloys Compd. 628, 130 (2015)

[13] Q.S. Yang, Z.J. Yu, H.C. Pan, Q.W. Dai, J.H. Li, Acta Metall. Sin. (Engl. Lett.) 29, 475 (2016)

[14] B. Song, G.S. Huang, H.C. Li, L. Zhang, G.J. Huang, F.S. Pan, J. Alloys Compd. 489, 475 (2010)

[15] I. Basu, T.A. Samman, Acta Mater. 96, 111 (2015)

[16] L. Wang, G. Huang, Q. Quan, P. Bassani, E. Mostaed, M. Vedani, F. Pan, Mater. Des. 63, 177 (2014)

[17] Y. Xin, X. Zhou, H. Chen, J.F. Nie, H. Zhang, Y. Zhang, Q. Liu, Mater. Sci. Eng. A 594, 287 (2014)

[18] P. Molnár, A. Ostapovets, A. Jäger, Mater. Des. 56, 509 (2014)

[19] S. Dong, Q. Yu, Y. Jiang, J. Dong, F. Wang, W. Ding, Mater. Des. 65, 762 (2015)

[20] S. Matsunaga, T. Kiguchi, K. Sato, T.J. Konno, Mater. Trans. 56, 923 (2015)

[21] S.H. Park, J.H. Lee, Y.H. Huh, S.G. Hong, Scr. Mater. 69, 797 (2013)

[22] L.L. Chang, Y.N. Wang, X. Zhao, M. Qi, Mater. Charact. 60, 991 (2009)

[23] J.R. Luo, Y.Q. Yan, J.S. Zhang, L.Z. Zhang, Acta Metall. Sin. (Engl. Lett.) 23, 827 (2016)

[24] D.F. Shi, T.M. Liu, L.Q. Zhang, D.W. Hou, H.C. Chen, F.S. Pan, L.W. Lu, Mater. Sci. Eng. A 667, 132 (2016)

[25] M.R. Barnett, Z. Keshavarz, A.G. Beer, D. Atwell, Acta Mater. 52, 5093 (2017)

[26] M.G. Jiang, H. Yan, R.S. Chen, Mater. Des. 891, 87 (2015)

[27] N. Bozzolo, F. Wagner, N. Dewobroto, T. Grosdidier, Mater. Sci. Forum 408, 901 (2002)

[28] Q.S. Yang, B. Jiang, Z.J. Yu, Q.W. Dai, S.Q. Luo, Acta Metall. Sin. (Engl. Lett.) 28, 1257 (2015)

[29] C. Wang, H. Ding, B.S. Wang, K. Wang, J.J. Shi, J.F. Chen, Acta Metall. Sin. (Engl. Lett.) 30, 921 (2017)

[30] Q.S. Yang, B. Jiang, Y. Tian, W.J. Liu, F.S. Pan, Mater. Lett. 100, 29 (2013)

[31] L. Chen, J.X. Zhang, J.W. Tang, G.J. Chen, G.Q. Zhao, C.S. Zhang, J. Mater, Process Technol. 346, 259 (2018)

[32] J. Bohlen, M.R. Nurnberg, J.W. Senn, D. Letzig, S.R. Agnew, Acta Mater. 55, 2101 (2007) 